3. Leppaniemi A. et al. 2019 WSES guidelines for the management of severe acute pancreatitis. World J Emerg Surg. 2019; 14, pp. 27.

4. Scherer J. et al. Issues in hypertriglyceridemic pancreatitis: an update", J Clin Gastroenterol. 2014; 48 (3), pp. 195-203.

5. Wang S. H. et al. Relationship between Plasma Triglyceride Level and Severity of Hypertriglyceridemic Pancreatitis. PLoS One. 2016; 11 (10), pp. e0163984.
6. Vipperla K. et al. Clinical Profile and Natural Course in a Large Cohort of Patients With Hypertriglyceridemia and Pancreatitis. J Clin Gastroenterol. 2017; 51 (1), pp. 77-85.

7. Hoàng Đức Chuyên. Nghiên cứu đặc điểm lâm sàng, cận lâm sàng và điều trị viêm tuy cấp do tăng triglyceride. Trường Đại học Y Hà Nô̂i. 2012.

8. Huỹnh Tấn Đạt. Vai trò của tăng Triglyceride trong viêm tụy cấp. Đại học Y Dược Thành Phố Hồ Chí Minh. 2012.

\title{
ĐĂC ĐIỂM SỬ DỤNG THUỐC ỨC CHẾ MIỄN DICCH SAU GHÉP VÀ MỐI LIÊN QUAN ĐẾN ĐÁI THÁO ĐƯỜNG SAU GHÉP THẬN
}

\section{TÓM TẮT}

Mục tiêu: Phân tích đặc điểm sử dụng thuốc ức chế miễn dịch và mối liên quan đến đái tháo đường sau ghép trên đối tượng 3 tháng sau ghép thận. Đối tượng và phương pháp nghiên cứu: Gổm 508 bệnh nhân có thời gian sau ghép thận $\geq 3$ tháng được theo dõi và điều tri sau ghép tai BV Viêt Đức, từ 09/2017 đến 04/2018. Tất cả các bệnh nhân đều tự nguyện tham gia nghiên cứu. Bệnh nhân được lấy máu vào buổi sáng trước khi ăn và uống thuốc ức chế miễn dịch. Chẩn đoán đái tháo đường sau ghép tạng dựa trên tiêu chuẩn của Hiệp hội Đái tháo đường Hoa Kỳ (ADA - American Diabetes Association). Tất cả các bệnh nhân đều được sử dụng phác đồ chống thải ghép 2- 3 thuốc trong 3 nhóm thuốc theo quy trình của Bộ y tế. Kết quả: Tỉ lệ sử dụng thuốc ức chế theo thứ tự từ cao đến thấp như sau: MMF/MPA (92,32\%); prednisolon $(91,54 \%)$; tarcrolimus $(81,50 \%)$; basiliximab (75,59\%); cyclosporin A (17,72\%); everolimus $(6,10 \%)$. Hầu hết đối tượng sử dung các thuốc kể trên không cho sự khác biệt giữa phát triển NODAT và không NODAT; chỉ ở đổi tượng sử dụng corticoid tỉ lệ bệnh nhân bị NODAT là $12,47 \%$ trong khi không NODÁT chiếm $87,53 \%$ sư khác biệt có ý nghĩa thống kê với $p<0,001$. Kết luận: Điều chỉnh chế độ sử dung thuốc ức chế miễn dịch đặc biệt là corticoid có thể làm thay đổi nguy cơ phát triển đái tháo đường sau ghép thận.

Tư khóa: thuốc ức chế miễn dịch, đái tháo đường sau ghép thận

\section{SUMMARY \\ CHARACTERISTICS OF IMMUNOSUPPRESSIVE DRUGS AND ASSOCIATION WITH NEW-ONSET DIABETES AFTER RENAL TRANSPLANTATION}

\footnotetext{
${ }^{1}$ Bệnh viện Quân y 103

${ }^{2}$ Học viện Quân y

Chịu trách nhiệm chính: Đặng Thành Chung

Email: dangthanhchung@vmmu.edu.vn

Ngày nhận bài: 4.01.2021

Ngày phản biện khoa học: 5.3.2021

Ngày duyệt bài: 15.3.2021
}

\section{Nguyễn Đức Thuận ${ }^{1}$, Đặng Thành Chung²}

Objectives: To analyze the use of immunosuppressant drugs and the association with new-onset diabetes after renal transplantation (NODAT) in subjects three months post-transplantation. Subjects and methods: Including 508 patients with kidney post-transplant more than three months who are followed up and treated at Viet Duc University Hospital from September 2017 to April 2018. All patients volunteered to participate in the study. Collect blood samples of recipients in the morning before eating and taking immunosuppressants. Patients were diagnosed with new-onset diabetes after renal transplantation based on the American Diabetes Association (ADA). All patients received an anti-rejection regimen according to the procedure of Vietnam's Ministry of Health. Results: The ratio of using immunosuppressive drugs from high to low order as follows: MMF/MPA (92.32\%); prednisolone (91.54\%); tacrolimus (81, .50\%); basiliximab (75.59\%); cyclosporin A (17.72\%); everolimus (6.10\%). Most of the patients using these drugs did not show the difference of rate between developing NODAT and non-NODAT; Only in patients using corticosteroids, the rate of patients with NODAT was $12.47 \%$ non-NODAT accounted for $87.53 \%$, the difference was statistically significant with $p$ $<0.001$. Conclusion: Modifying an immunosuppressant regimen, especially corticoid, may alter the risk of developing diabetes after kidney transplantation.

Keywords: Immunosuppressive drugs, new-onset diabetes after renal transplantation.

\section{I. Đă̆T VẤN ĐỀ}

Mối liên quan giữa đái tháo đường mới mắc sau ghép thận (New-onset diabetes after transplantation - NODAT) và thuốc ức chế miễn dịch sử dụng sau cây ghép đã được ghi chép lại rõ̃ rệt [1], và là yếu tố chiếm tới $74 \%$ nguy cơ phát triển NODAT [2].Các tác nhân có liên quan nhiều nhất với NODAT là corticosteroid và tacrolimus $[3,4]$. Tăng kháng insulin và tăng cân được xem như là cơ chế chính liên quan đến corticosteroid gây ra NODAT [3]. Sự liên quan giữa corticosteroids và NODAT chủ yếu phụ 
thuộc vào liêu lượng tích lũy và thời gian điều trị [5]. Tacrolimus đã được báo cáo là có tác dụng gây bệnh đái tháo đường cao hơn cyclosporine. Trong nghiên cứu của Woodward và cộng sự đã phát hiên tỉ lê mắc NODAT sau ghép là $18 \%$ ở những người dùng cyclosporine và $30 \%$ ở nhóm người điêu trị bằng tacrolimus [6]. Có một chi tiết khá thú vị khi có những nghiên cứu cho thây tacrolimus gây đái tháo đường cũng phụ thuộc vào sắc tộc; trên thực tế, một số nghiên cứu tiến hành ở Trung Quốc cho thấy tỉ lệ phát triển NODAT thấp khi điều trị bằng tacrolimus $[7,8]$. Để giảm nguy cơ NODAT, việc chuyển đổi các chất ức chế calcineurin thành sirolimus đã được đưa ra. Tuy nhiên, khi sử dụng sirolimus lại cho thây tî lệ bị tiều đường cao hơn, thông qua cơ chế do phản ứng bù đắp của tế bào beta tuyến tụy và giảm độ nhạy của insulin [9]. Suy giảm chuyển hóa glucose cũng được ghi nhận ở những người sau ghép thận được điều trị bằng basiliximab, một kháng thể CD25 gián tiếp ức chế sự tăng sinh của tế bào $T$, như là liệu pháp điều trị cảm ứng khi ghép. Trong nhóm bệnh nhân điều trị bằng basiliximab có $51,5 \%$ bệnh nhân đã phát triển NODAT, giảm dung nạp glucose, hoặc giảm đường huyết lúc đói, so với 36,9\% ở nhóm không sử dụng dẫn nhập trị liệu, nhưng cơ chế bệnh sinh vẫn chưa được làm sáng tỏ.

Nghiên cứu này nhằm phân tích mối liên quan giữa chế độ sử dụng thuốc ức chế miễn dịch chống thải ghép và nguy cơ NODAT ở những người sau ghép thận 3 tháng. Những phát hiện này có thể cung cấp cơ sở để điều chỉnh phác đồ sử dụng thuốc ức chế miễn dịch đối với những người sau ghép thận có nguy cơ mắc NODAT.

\section{II. ĐỐI TƯỢNG VÀ PHƯƠNG PHÁP NGHIÊN CỨU}

2.1 Đối tượng nghiên cứu: 508 bệnh nhân có thời gian sau ghép thận $\geq 3$ tháng được theo dõi và điêuu trị sau ghép tại BV Việt Đức. Thời gian nghiên cứu từ 09/2017 đến 04/2018. Tất cả các bệnh nhân đều tự nguyện tham gia nghiên cứu.

2.2 Phương pháp nghiên cứu: Bệnh nhân được lấy máu vào buổi sáng trước khi ăn và uống thuốc ức chế miễn dịch.

Tiêu chuẩn chẩn đoán đái tháo đường sau ghép tạng: dựa trên tiêu chuẩn của Hiệp hội Đái tháo đường Hoa Kỳ (ADA - American Diabetes Association) đối với đái tháo đường tuýp 2, như sau: Glucose huyết tương lúc đói (nhịn ăn trước thời điểm xét nghiệm ít nhất 8 tiếng) $\geq 7,0$ $\mathrm{mmol} / \mathrm{L}(126 \mathrm{mg} / \mathrm{dL}) /$ hoặc Glucose huyết tương trong 2 giờ sau Nghiệm pháp gây tăng đường huyết theo đường uống (OGTT - Oral glucose tolerance test) $\geq 11.1 \mathrm{mmol} / \mathrm{L}(200 \mathrm{mg} / \mathrm{dL}) /$ hoặc Glucose huyết tương bình thường $\geq$ $11.1 \mathrm{mmol} / \mathrm{L}(200 \mathrm{mg} / \mathrm{dL})$, ở 3 lần đo khác nhau.

Phác đồ sử dụng thuốc chống thải ghép: Tất cả các bệnh nhân đều được sử dụng phác đồ chống thải ghép 2- 3 thuốc trong 3 nhóm thuốc theo quy trình của Bộ y tế .

- Dẫn nhập: Basiliximab tùy theo độ hòa hợp HLA.

Duy trì: (Cyclosporin A hoặc Prograf) + (Cellcept/Myfortic hoặc Everolimus) + (Prednisolon hoặc không).

Sau khi các thông tin và số liệu đã được thu thập đầy đủ tiến hành phân tích trình bày dưới dạng tần suất và tỷ lệ phần trăm. So sánh trung bình giữa các biến phân nhóm và biến nhị phân. Tính chỉ số nguy cơ OR (Odds Ratio): bảng tiếp liên $2 \times 2$. Số liệu được xử lý theo các thuâtt toán thông kê y học sử dụng phần mềm Stata 12.0 với $p<0,05$ sẽ được chấp nhận là sự khác biệt có ý nghĩa thống kê.

\section{KẾT QUẢ NGHIÊN CỨU}

Bảng 1. Phân bố đôi tượng nghiên cứu theo loại thuốc chống thải ghép sử dụng.

\begin{tabular}{|c|c|c|c|}
\hline Loại thuốc & $\begin{array}{c}\text { Số lướng } \\
\text { (n) }\end{array}$ & $\begin{array}{c}\text { Tống } \\
\text { số }\end{array}$ & $\begin{array}{c}\text { Tỷ lệ } \\
(\mathbf{\%})\end{array}$ \\
\hline Cyclosporin A & 90 & 508 & 17,72 \\
\hline Tacrolimus & 414 & 508 & 81,50 \\
\hline MMF/MPA & 469 & 508 & 92,32 \\
\hline Everolimus & 31 & 508 & 6,10 \\
\hline Prednisolon & 465 & 508 & 91,54 \\
\hline Basiliximab & 288 & 381 & 75,59 \\
\hline
\end{tabular}

Nhận xét: Trong số các thuốc chống thải ghép sử dụng, sử dụng nhiều nhất có MMF/MPA, Prednisolon, và Tacrolimus với tỉ lệ sử dụng lần lượt là $92,32 \%, 91,54 \%$ và $81,50 \%$; sử dụng ít nhất là Everolimus với 6,1\%. Có 288 bệnh nhân trong số 381 người có thông tin sử dụng dẫn nhập Basiliximab chiếm 75,79\% bệnh nhẩn.

Bảng 2: Liên quan giữa sử dụng corticoid và NODAT

\begin{tabular}{|c|c|c|c|c}
\hline Corticoid & Đang dùng n(\%) & Đã dừng n(\%) & p & OR \\
\hline NODAT & $58(12,47)$ & $20(46,51)$ & & \multirow{2}{*}{0,164} \\
\cline { 1 - 3 } Không NODAT & $407(87,53)$ & $23(53,49)$ & \multirow{2}{*}{$<001$} & \multirow{2}{*}{$0,13(\mathbf{1 0 0})$} \\
\hline Tống số & $\mathbf{4 6 5 ( 1 0 0 )}$ & & \\
\hline
\end{tabular}


đường viêm gan nên 43 bệnh nhân được ngừng corticoid. Trong 465 bệnh nhân đang corticoid, có 58 bệnh nhân có NODAT chiếm 12,47\%. Tỷ lệ bệnh nhân đang dùng corticoid trong nhóm có NODAT và không có NODAT là khác biệt có ý nghĩa thống kê, độ tin cậy $95 \%$ với $p<0,001$

Bảng 3: Liên quan giứa sử dụng Cyclosporine và NODAT.

\begin{tabular}{|c|c|c|c|c|c|}
\hline Cyclosporine & NODAT $(n, \%)$ & Không NODAT $(n, \%)$ & Tống số & $\mathbf{p}$ & OR \\
\hline Có & $17(18,89)$ & $73(81,11)$ & $90(100)$ & 0,305 & \multirow{2}{*}{1,36} \\
\hline Không & $61(14,59)$ & $357(85,41)$ & $418(100)$ & & \\
\hline
\end{tabular}

Nhận xét: Trong 90 bệnh nhân có dùng cyclosporine, có 17 bệnh nhân có NODAT chiếm 18,89\%.

Tỷ lệ bệnh nhân NODAT trong nhóm có sử dụng và không sử dụng cyclosporine $A$ là như nhau.

Khác biết không có ý nghĩa thống kê với $\mathrm{p}=0,305>0,05$

Bảng 4: Liên quan giữa sử dụng Tacrolimus với NODAT.

\begin{tabular}{|c|c|c|c|c|c|}
\hline Tacrolimus & NODAT (n, \%) & Không NODAT (n, \%) & Tống số & p & OR \\
\hline Cón & $61(14,73)$ & $353(85,27)$ & $414(100)$ & 0,416 & \multirow{2}{*}{0,078} \\
\hline Không & $17(18,09)$ & $77(81,91)$ & $94(100)$ & & \\
\hline
\end{tabular}

Nhận xét: Trong 414 bệnh nhân dùng tacrolimus có 61 bệnh nhân NODAT, chiếm 14,73\%

Tỷ lệ bệnh nhân NODAT trong nhóm có và không sử dung tacrolimus là như nhau. Khác biệt không có ý nghĩa thống kê với $p=0,416>0,05$

Bảng 5: Liên quan giữa sử dụng MMF/MPA với NODAT.

\begin{tabular}{|c|c|c|c|c|c|}
\hline MMF/MPA & NODAT (n, \%) & Không NODAT (n, \%) & Tống số & P & OR \\
\hline Có & $76(16,20)$ & $393(83,80)$ & $469(100)$ & \multirow{2}{*}{0,065} & 3 \\
\cline { 1 - 5 } & $2(5,13)$ & $37(94,87)$ & $39(100)$ & \\
\hline
\end{tabular}

Nhận xét: Trong 469 người dùng MMF/MPA, có 76 bệnh nhân có NODAT chiếm 16,20\%. Tỷ lệ bệnh nhân NODAT trong nhóm có và không điêuu trị MMF/MPA là như nhau. Khác biệt không có ý nghĩa thống kê với $p=0,065$

Bảng 6: Liên quan giữa sử dụng Everolimus với NODAT.

\begin{tabular}{|c|c|c|c|c|c|}
\hline Everolimus & NODAT (n, \%) & Không NODAT (n, \%) & Tống số & p & OR \\
\hline Có & $2(6,45)$ & $29(93,55)$ & $31(100)$ & \multirow{2}{*}{0,202} & 0,364 \\
\hline Không & $76(15,93)$ & $401(84,07)$ & $477(100)$ & & \\
\hline
\end{tabular}

Nhận xét: Trong 31 người dùng everolimus, có 2 bệnh nhân có NODAT, chiếm 6,45\%. Tỷ lệ bệnh nhân NODAT trong nhóm có và không sử dụng evrolimus là như nhau. Khác biệt không có ý ghĩa thống kê với $p=0,202$

Bảng 7: Liên quan giữa sử dụng Basilixiamab với NODAT.

\begin{tabular}{|c|c|c|c|c|c|}
\hline Basiliximab & NODAT (n, \%) & Không NODAT (n, \%) & Tống số & P & OR \\
\hline Có & $43(14,93)$ & $245(85,07)$ & $288(100)$ & 0,311 & 1 \\
\hline Không & $10(10,75)$ & $83(89,25)$ & $93(100)$ & \\
\hline
\end{tabular}

Nhận xét. Trong nhóm bệnh nhân có điều trị basiliximab, có 43 bệnh nhân có NODAT chiếm $14,93 \%$. Tỷ lệ NODAT giữa nhóm có và không điều trị basiliximab là như nhau. Khác biệt không có ý nghĩa thống kê với $p=0,311$

\section{BÀN LUÂ̂N}

Các thuốc ức chế miễn dịch sử dụng sau ghép thận được cho là yếu tố nguy cơ gây NODAT, lí do được cho là có thể gây độc tế bào $\beta$ làm suy yếu khả năng bù trừ hormone dẫn đến rối loạn chuyển hóa glucose. Trong nghiên cứu của chúng tôi theo thống kê thu được tỉ lệ sử dụng theo thứ tự từ cao đến thấp như sau: MMF/MPA (92,32\%); prednisolon (91,54\%); tarcrolimus $(81, .50 \%)$; basiliximab $(75,59 \%)$; cyclosporin A $(17,72 \%)$; everolimus $(6,10 \%)$. Trong đó corticosteroids vẫn là thuốc sử dụng chính ức chế miễn dịch sau ghép và là một phần của hầu hết các phác đồ điều trị. Nguy cơ phát triển NODAT liên quan đến sử dụng steoroid bao gồm cả liều và thời gian sử dụng [2]. Steroids kích hoạt tân tạo glucose từ phân cắt protein hoặc lipid (không phải từ sản phẩm carbonhydrate, còn gọi là gluconeogenesis) và phân giải glucose, gây tăng cả đường huyết lúc đói và sau bữa ăn. Giảm tân tạo glycogen, kháng insuline sử dụng sau khi ghép thận là một một trong những ảnh hưởng quan trọng của liệu pháp steroid, ngoài ra còn gây rối loạn chức năng tế bào $\beta$. Liều của steroid cũng đã được chỉ ra có liên quan đến mức đường huyết.

Tacrolimus và cyclosporine là thuốc ức chế calcineurin (calcineurin-inhibitor: CNI) được sử dụng rộng rãi sau ghép thận. Hầu hết bệnh nhân đều được sử dụng một trong hai thuốc như một 
phần của chễ đô điều trị ức chế miễn dịch. Trong số hai thuốc trên thì tacrolimus được cho rằng có nguy cơ gây đái tháo đường nhiều hơn, khoảng 50\%. Không giống như steroid, các thuốc này khả năng gây tăng đường huyết không phụ thuộc vào liều, mặc dù điều này vẫn còn tranh cãi. Tacrolimus là thuốc ức chế calcineurin đang ngày càng được ưu tiên sử dụng tại hầu hết các trung tâm ghép do ưu điểm hiệu quả và an toàn, mặc dù có nguy cơ gây đái tháo đường. Sự thiếu hụt calcinerin dẩn đến giảm sản xuất insuline. CNI ức chế sự hấp thụ glucose ở tế bào do giảm số lượng thụ thể vận chuyển glucose loại 4 (GLUT-4) trên bề mặt tế bào mõ. GLUT-4 là một protein điều tiết insuline có mặt chủ yếu ở mô mỡ và cơ, giúp vận chuyển glucose vào tế bào chất của tế bào. Do đó, việc giảm GLUT-4 dễn đến tăng đường huyểt. Tacrolimus còn giảm hoạt động của enzyme glucokinase tại tiểu đảo tụy, vì thế ức chế việc giải phóng insuline nhờ xúc tác từ glucose. Ngoài hai cơ chế làm ức chế giải phóng insuline và tăng kháng insuline ở mô kể trên, sử dụng CNI được chỉ ra làm phù nề tế bào chất và không bào, biến đổi insuline, ngoài ra CNI còn được cho là ức chế biểu hiện gene mã hóa insuline.

Cũng trong nghiên của này của chúng tôi khi xét mối liên quan của các thuốc kể trên với sự phát triển NODAT, kết quả cho thây hầu hết đối tượng sử dụng các thuốc kể trên không cho sự khác biệt giữa phát triển NODAT và không NODAT; chỉ ở đối tượng sử dụng corticoid tỉ lệ bênh nhân bi NODAT là $12,47 \%$ trong khi không NODAT chiếm $87,53 \%$ sự khác biệt có ý nghĩa thống kê với $p<0,001$. Tỉ lệ NODAT cao ở nhóm không dùng corticoid ở thời điểm hiện tại cũng là do trong nhóm đã được chẩn đoán NODAT trước đây đã được dừng corticoid để tránh tăng đường huyết khó kiểm soát. Kết quả của chúng tôi không giống như những báo cáo đã trình bày ở trên, có lẽ do thời điểm khảo sát, hầu hết các đối tượng đã được can thiệp điều trị tình trạng đái tháo đường vì thế có thể ảnh hưởng nhiều đến việc đối chiếu so sánh.

\section{KẾT LUÂ̂N}

Điều chỉnh chế độ sử dụng thuốc ức chế miễn dịch đặc biệt là corticoid có thể làm thay đổi nguy cơ phát triển đái tháo đường sau ghép thận.

\section{TÀI LIẸU THAM KHẢO}

1. Luan, F.L., D.E. Steffick, and A.O. Ojo, Newonset diabetes mellitus in kidney transplant recipients discharged on steroid-free immunosuppression. Transplantation, 2011. 91(3): p. 334-41.

2. Rodrigo, E., et al., New-onset diabetes after kidney transplantation: risk factors. J Am Soc Nephrol, 2006. 17(12 Suppl 3): p. S291-5.

3. Kamar, N., et al., Diabetes mellitus after kidney transplantation: a French multicentre observational study. Nephrol Dial Transplant, 2007. 22(7): p. 1986-93.

4. Vincenti, F., et al., Results of an international, randomized trial comparing glucose metabolism disorders and outcome with cyclosporine versus tacrolimus. Am J Transplant, 2007. 7(6): p. 1506-14.

5. Davidson, J., et al., New-onset diabetes after transplantation: 2003 International consensus guidelines. Proceedings of an international expert panel meeting. Barcelona, Spain, 19 February 2003. Transplantation, 2003. 75(10 Suppl): p. Ss3-24.

\section{NGHIÊN CỨU HÌNH ẢNH VÕNG MAC VÙNG HOÀNG ĐIỂM BẰNG OCT SAU PHẪU THUÂ̂T BONG VÕ்NG MẠC QUA HOÀNG ĐIỂM}

\section{TÓM TẮT}

Mục tiêu: Ngiên cứu nhằm Mô tả hình ảnh võng mạc vùng hoàng điểm bằng $\mathrm{OCT}$ trên bệnh nhân bong võng mạc qua hoàng điểm đã được điều trị và tìm hiểu một số yếu tố liên quan với tình trang võ̉ng mac vùng hoàng điểm. Thiết kế nghiên cứu: nghiên cứu

\footnotetext{
${ }^{1}$ Đai hoc Y Hà Nôi

${ }^{2}$ Bềnh viện mắt Trung Uơng

Chịu trách nhiệm chính: Nguyễn Thị Phương Thảo Email: nguyenthaovnio@gmail.com

Ngày nhận bài: 6.01.2021

Ngày phản biên khoa hoc: 4.3.2021

Ngày duyệt bài: 15.3.2021
}

Nguyễn Thị Phương Thảo ${ }^{1}$, Cung Hồng Sơn ${ }^{2}$ mô tả tiến cứu theo dõi dọc. Đối tượng và phương pháp: 31 mắt có $B V M$ có bao gồm hoàng điểm, có vết rách nguyên phát được điêu trị ở Bệnh Viện Mắt Trung Ương từ tháng 1 - 2014 đến tháng $7-2014$. PT thành công bằng CDK hoăc đai độn CM. Thời gian nhìn mờ $\leq 30$ ngày. Lập hồ sơ đánh giá thời gian xuất hiện triệu chứng, phương pháp phẫu thuật... Tiến hành khám bênh nhân đo thỉ lực, làm OCT của bênh nhân trên các thời điểm khám sau PT 6 tuân và 3 tháng để đánh giá tình trang VM vùng hoàng điểm bao gồm thay đổi hình thái và vi cấu trúc VM và tìm hiểu 1 số yếu tố liên quan đến những bất thường này. Kết quả: bất thường hình thái vùng hoàng điểm trên OCT: $12 / 31$ mắt $(38,7 \%)$ trong đó dịch dưới võng mạc(DDVM) hay gặp nhất $10 / 31$ mắt $(32,3 \%)$ sau 6 